\title{
Books on the economic history of Vietnam
}

\author{
Ho Manh Toan
}

AISDL

Hanoi, January 11, 2021

Vietnam should teach economics to high school students [1]. The need for this subject is apparent. However, where should we begin? Indeed, classic works, or at least certain passages, are recommendable. A simple search on Google can point you to a lot of good selections [2-5]. However, this is the easy part. How about books on Vietnam's economy, especially the economic history of Vietnam. High school is a great opportunity to study basic knowledge and get to know about history.

This short paper presents some important books, which are more or less accessible using the Internet, on Vietnam's economic history for a later recommendation. The criteria are relatively straightforward: a book should be in Vietnamese, and it should cover different eras of Vietnam's economy, and textbooks are excluded. The author used the National Library of Vietnam's book database as the main source. Google and Worldcat were also used to find more results. The keywords are: "Lịch sử Kinh tế Việt Nam," "Kinh tế Việt Nam."

The finding from a quick desktop survey is shown in Table 1.

Table 1. Books on the economic history of Vietnam

\begin{tabular}{|l|l|l|l|l|l|}
\hline & Book & Year & Period & Authors & Ref \\
\hline 1 & $\begin{array}{l}\text { Lịch sử Kinh tế Việt Nam 1945 } \\
-2000 \text { (2 Volumes) }\end{array}$ & 2002 & $\begin{array}{l}1945- \\
2000\end{array}$ & Đặng Phong & {$[6]$} \\
\hline 2 & Lịch sử Kinh tế Việt Nam & 2003 & $\begin{array}{l}\text { Beginning } \\
-2000\end{array}$ & Phạm Văn Chiến & {$[7]$} \\
\hline 3 & $\begin{array}{l}\text { Lịch sử tín dụng nông nghiệp } \\
\text { Việt Nam, 1875-1945 }\end{array}$ & 1997 & $\begin{array}{l}1875- \\
1945\end{array}$ & Phạm Quang Trung & {$[8]$} \\
\hline 4 & $\begin{array}{l}\text { Lịch sử nền kinh tế quốc dân } \\
\text { Việt Nam }\end{array}$ & 2002 & $\begin{array}{l}\text { Feudalism } \\
- \text { Present }\end{array}$ & Thế Đạt & {$[9]$} \\
\hline 5 & $\begin{array}{l}\text { Kinh tế Việt Nam từ cách } \\
\text { mạng tháng tám đến kháng } \\
\text { chiến thắng lợi }\end{array}$ & 1966 & $\begin{array}{l}8 / 1945- \\
1954\end{array}$ & Nguyễn Ngọc Minh & {$[10]$} \\
\hline 6 & $\begin{array}{l}\text { Kinh tế Việt Nam: Thăng trầm } \\
\text { và đột phá }\end{array}$ & 2009 & $\begin{array}{l}1945- \\
2008\end{array}$ & $\begin{array}{l}\text { Phạm Minh Chính; } \\
\text { Vương Quân Hoàng }\end{array}$ & {$[11]$} \\
\hline
\end{tabular}




\begin{tabular}{|l|l|l|l|l|l|}
\hline 7 & Kinh Tế Việt Nam, 1945-1960 & 1960 & $\begin{array}{l}1945- \\
1960\end{array}$ & $\begin{array}{l}\text { Viện Kinh Tế Thuộc } \\
\text { Uy Ban Khoa Học } \\
\text { Nhà Nước }\end{array}$ & [12] \\
\hline
\end{tabular}

Some books are probably available in bibliographic information only $[10,12]$. Meanwhile, the most updated book that I can find was published 12 years ago already [11].

Indeed, the list is by no means exhaustive. But by all means, the table is very short. In 2020, according to IMF calculation, Vietnam's gross domestic products (GDP) in dollar terms, PPP-adjusted, for the first time in its history exceeded US\$1,005 billion. The country's population becomes close to 100 million. Its stock markets' daily trade value reached almost US\$ 1 billion a day for the first week of 2021.

Apparently, for an emerging economy with growing regional importance like Vietnam, the above list of books falls short of our expectations. It is proof that a big gap will certainly need to be filled. For economics, predicting the future is always a hard job. Nonetheless, failing to learn from the past lessons will make the job even harder.

\section{References}

[1] Ho, M. T. (2021). No money, no honey. OSF Preprints, DOI: 10.31219/osf.io/zw6k7

[2] Silver, D. (2006). High School Money Book. Adams-Hall Publishing

[3] Lopus, J. S., \& Willis, A. M. (Eds.). (2003). Economics in Action: 14 Greatest Hits for Teaching High School Economics. Council for Economic Education.

[4] Harris, R. (1997). Who Taught You about Money: A Fun Book for Young People. Hampton Roads Publishing.

[5] Mayer, D. A. (2010). The Everything Economics Book: From Theory to Practice, Your Complete Guide to Understanding Economics Today. Simon and Schuster.

[6] Phong, Đ. (2002). Lịch sử Kinh tế Việt Nam 1945 - 2000. Nxb Khoa học Xã hội.

[7] Chiến, P. V. (2003). Lịch sử Kinh tế Việt Nam. Nxb Đại học Quốc gia Hà Nội.

[8] Trung, P. Q. (1997). Lịch sử tín dụng nông nghiệp Việt Nam, 1875-1945. Nxb Khoa học Xã hội. 
[9] Đạt, T. (2002). Lịch sử nền kinh tế quốc dân Việt Nam. Nxb Hà Nội.

[10] Minh, N. N. (1966). Kinh tế Việt Nam từ cách mạng tháng tám đến kháng chiến thắng lợi. Nxb Khoa học.

[11] Chính, P. M., \& Hoàng, V. Q. (2009). Kinh tế Việt Nam: Thăng trầm và đột phá. Nxb Chính trị Quốc gia, Hà Nội.

[12] Viện Kinh Tế Thuộc Ủy Ban Khoa Học Nhà Nước. (1960). Kinh Tế Việt Nam, 1945-1960. Nxb Sự thật. 